\title{
Energy Control Center (ECC) for DERS Using Multi-Agent System by Soft Computing Technique
}

\author{
V. Sravani ${ }^{1}$, K. Dharanisree ${ }^{2}$ \\ ${ }^{1}$ PG Scholar, M. Tech, Electrical Power Systems, Sri Venkateswara College of Engineering and Technology, Chitoor-517127, AP, India \\ ${ }^{2}$ Assistent Professor, M. Tech, Sri Venkateswara College of Engineering and Technology, Chitoor-517127, AP, India
}

\begin{abstract}
The main objective of this project is to discuss the design and implementation of a multi-agent system that provides intelligence to a distributed smart grid because of their benefits of extensibility, autonomy, reduced maintenance, etc. In the literature the smooth operation of a power system requires a control architecture that consists of hardware and software protocols for exchanging system status and control signals. This project presents the modeling of intelligent energy control center (ECC) controlling Distributed Energy Resources (DERs) using a multi-agent system. The multi-agent system consist of smart grid and agents such as user agent, distributed energy resources (DER) agent, database agent, control agent, work in collaboration to perform assigned tasks. The DER model is created on the client side and ECC is created on the server side. These results indicate that the controlling of DER agent can be achieved both from server and client. The wind power generator connected with local load, the solar power connected with local load and battery and the ECC controlled by Artificial Neuro Fuzzy Interface System (ANFSI) is used in PV system for reducing the transmission and distribution losses, complexity and increases efficiency and THD and are simulated in MATLAB/SIMULINK.
\end{abstract}

Keywords: Distributed energy resources (DER) and internet protocol (IP), distributed generators (DGs), energy control center (ECC), Artificial Neuro Fuzzy Interface System (ANFSI)

\section{Introduction}

Multi-Agent systems (MAS) consist of multiple intelligent agents that interact to solve problems that may be beyond the capabilities of a single agent or system. For many years, conceptual MAS designs and architectures have been proposed for applications in power systems and power engineering. With the increasing use and modeling of distributed energy resources for microgrid applications, MAS are well suited to manage the size and complexity of these energy systems. The recent trend of renewable energy development is a combination of distributed power sources and energy storage subsystems to form a small microgrid that can reduce loss of energy from power transmission lines over long distances. To use renewable energy more efficiently, dc electricity should be directly supplied to these loads. Energy Control Center (ECC)) is designed and built for system operation. In order to have an efficient power system operation and control, various control centers have to be operated in the hierarchical level. The following Table-1 shows the level decomposition of control centers in the power system.

Table 1: Level Decomposition of Control Centers

\begin{tabular}{|c|c|c|}
\hline Level & System & Monitoring \& Control \\
\hline First & $\begin{array}{c}\text { Generating Stations, } \\
\text { Substations }\end{array}$ & Local Control Center \\
\hline Second & $\begin{array}{c}\text { Sub transmission \& } \\
\text { Transmission Network }\end{array}$ & $\begin{array}{c}\text { Area Load Dispatch } \\
\text { Centre }\end{array}$ \\
\hline Third & Transmission System & $\begin{array}{c}\text { State Load Dispatch } \\
\text { Centre }\end{array}$ \\
\hline Fourth & $\begin{array}{c}\text { Interconnected power } \\
\text { System }\end{array}$ & Regional Control Center \\
\hline
\end{tabular}

\section{Description of Energy Control Center and Multi-Agent System}

A multi-agent system which stands a few steps ahead of a SCADA system is used to manage the grid. The component of multi-agent system and their functionality are given in block diagram is shown in Fig. 1.The server has a wireless connection with the client as shown in Fig. 1. This communication enables a DER agent (from the client side) to manage the power that is to be distributed to the necessary loads. DER agent, solar and wind power generator are connected to ECC through the Internet. This data is stored in database agent in ECC. The control action is taken by the ANFIS present in ECC, based on the data from the DER. In this work, internet is used for communication

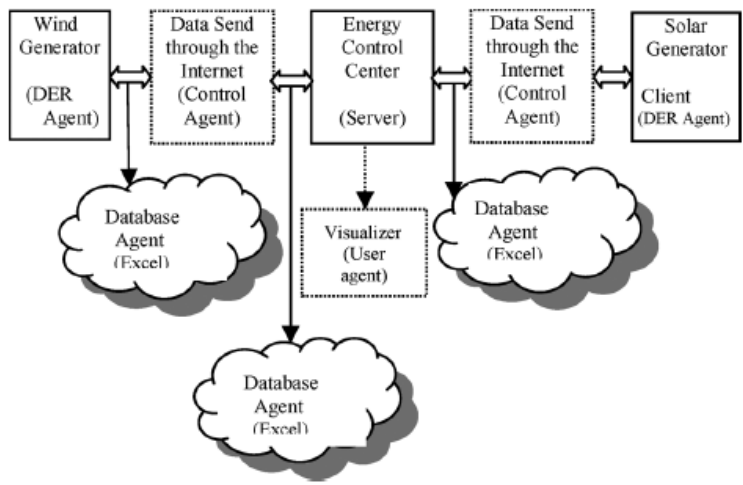

Figure 1: Block diagram of ECC

The multi-agent system operations are shown in Fig. 2. Consist of User agent, control agent and DER agent communicate with the database agent. This database is sent to the server through a Remote Terminal Unit (RTU) like a conventional SCADA system. RTUs are special purpose computers which contain analog to digital converters (ADC) and digital to analog converters (DAC). These converters' 


\section{International Journal of Science and Research (IJSR) \\ ISSN (Online): 2319-7064 \\ Index Copernicus Value (2013): 6.14 | Impact Factor (2015): 6.391}

digital inputs are used to get the status and outputs are used to control. The visualizer receives copies of all messages exchanged within the multi-agent system.

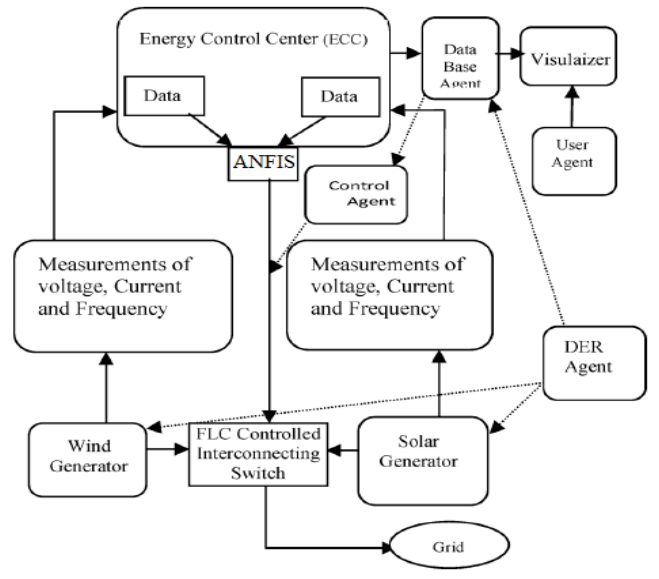

Figure 2: Operation of multi-agent

A multi-agent system controls and monitors the DER for power delivery. It is used for monitoring the voltage, load management, energy management, automated meter reading and substation control.

\section{Block Diagram of the Simulation Model}

The block diagram of the multi-agent system simulation model is given in Fig. 3. Wind power generation consists of a wind mill, induction generator connected to the grid through circuit breaker and the load. Solar power generation consists of solar panel, inverter, transformer connected to the load and circuit breaker. The interconnection of wind power, solar power and grid forms the power system smart grid with DER. The voltage measured in wind power generator and solar power generator is sent to ECC through the Internet. The Artificial Neuro Fuzzy Interface (ANFIS) present in ECC activates the circuit breaker according to the voltage requirement. The addition/removal of solar panels to the grid is controlled by ANFIS. If solar panel is removed from the grid, it will be connected to charge the battery. Since ANFIS is used for the control, it can be extended to control circuit breaker (CB-1) and circuit breaker (CB-2), as given in Fig. 3 , depending upon the availability of DERs.

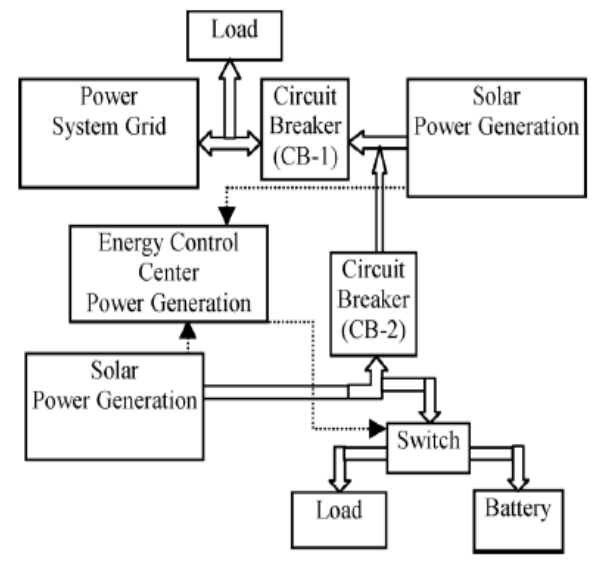

Figure 3: Block diagram of power system interconnected with wind and solar power generation scheme
In this work, simulation model of wind power generator is created in computer-1 as shown in Fig. 4. It is considered as client. The voltage, current, frequency and power of DER can be measured. This is known as DER agent. It is converted in to excel sheet using MATLAB commands which is called data-base agent. This can be sent through the Internet to computer-2, which is a server. In this computer, solar power generation SIMULINK model is created and ECC is also developed in different file.ECC can be developed in either computer-1 or 2 . Based on the voltage magnitude received in ANFIS, the decision will be taken whether solar power should be used for charging battery or connected to grid/load.

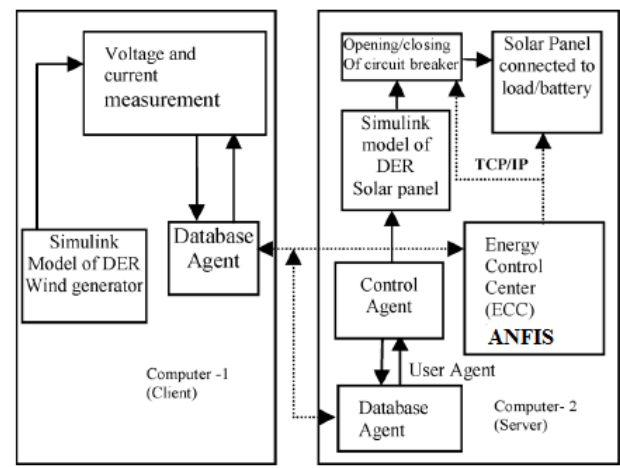

Figure 4: Representation of multi-agent system.

The circuit breaker (CB-1) is connecting wind power generation to grid. The circuit breaker (CB-2) is connecting solar power generation to grid. To utilize the maximum power from solar panel, switch is used to connect the solar power to local load or charging the battery as shown in Fig. 3 .

\section{Design of ANFIS}

ANFIS is a simple data learning technique that uses a fuzzy inference system model to transform a given input into a target output. This prediction involves membership functions, fuzzy logic operators and if -then rules. There are two types of fuzzy system, commonly known as the Mamdani and Sugeno models. There are five main processing stages in the ANFIS operation, including input fuzzification, application of fuzzy operators, application method, output aggregation and de-fuzzification.

\section{ANFIS Architecture}

Generally, ANFIS is a multilayer feed forward network in which each node performs a particular function (node function) on incoming signals. For simplicity, we consider two inputs ' $x$ ' and ' $y$ ' and one output ' $z$ '. Suppose that the rule base contains two fuzzy if-then rules of Takagi and Sugeno type

Rule 1: IF $\mathrm{x}$ is $\mathrm{A} 1$ and $\mathrm{y}$ is $\mathrm{B} 1 \mathrm{THEN} \mathrm{f} 1=\mathrm{P} 1 \mathrm{x}+\mathrm{Q} 1 \mathrm{y}+\mathrm{R} 1$

Rule 2: IF $x$ is $A 2$ and $y$ is $B 2$ THEN $f 2=P 2 x+Q 2 y+R 2$

The ANFIS architecture is a five layer feed forward network is given as

Layer 1: Every node in this layer is a square node with a node function (the membership value of the premise part) 


\section{International Journal of Science and Research (IJSR) \\ ISSN (Online): 2319-7064}

Index Copernicus Value (2013): 6.14 | Impact Factor (2015): 6.391

\section{$\mathrm{Oi}=\mu \mathrm{Ai}(\mathrm{X})$}

Where, $\mathrm{x}$ is the input to the node $\mathrm{i}$, and $\mathrm{Ai}$ is the linguistic label associated with this node function.

Layer 2: Every node in this layer is a circle node labeled which multiplies the incoming signals. Each node output represents the firing strength of a rule.

$$
\operatorname{Oi} 2=\mu \operatorname{Ai}(X) \mu \operatorname{Bi}(Y) \text { where } i=1: 2
$$

Layer 3: Every node in this layer is a circle node labeled $\mathrm{N}$ (normalization). The ith node calculates the ratio of the ith rule's firing strength to the sum of all firing strengths.

$$
\text { Oi3 }=\mathrm{W}=w 1 /(w 1+w 2), \text { where } \mathrm{i}=1: 2
$$

Layer 4: Every node in this layer is a square node with a node function

$$
\mathrm{Oi4}=\mathrm{W}(\mathrm{PiX}+\mathrm{QiY}+\mathrm{Ri})
$$

Layer 5: The single node in this layer is a circle node labeled that computes the overall output as the summation of all incoming signals

Oi5 $=$ System output, where $\mathrm{i}=1: 2$

\section{ANFIS Learning Algorithm}

The ANFIS Learning Algorithm uses a two-pass learning cycle. In the forward pass, S1 is unmodified and S2 is computed using a Least Squared Error (LSE) algorithm (Off-line Learning). In the Backward pass, S2 is unmodified and S1 is computed using a gradient descent algorithm (usually Back Propagation). From the ANFIS structure shown in Figure5, it has been observed that when the values of the premise parameters are fixed, the overall output can be expressed as a linear combination of the consequent parameters.

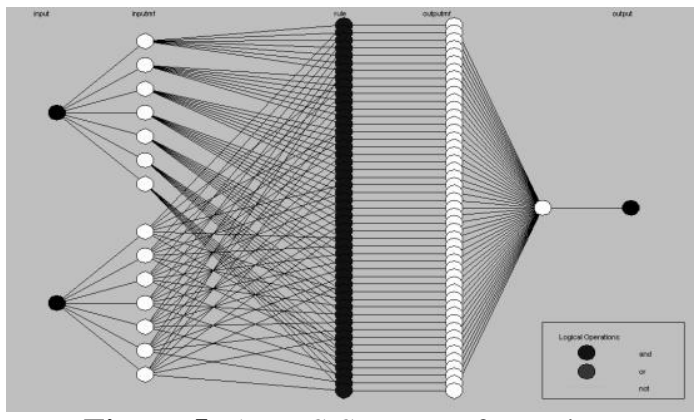

Figure 5: ANFIS Structure formation

The hybrid learning algorithm is a combination of both back propagation and the least square algorithms. Each epoch of the hybrid learning algorithm consists of two passes, namely forward pass and backward pass. In the forward pass of the hybrid learning algorithm, functional signals go forward up to layer 4 and the consequent parameters are identified by the least squares estimate. The back propagation is used to identify the nonlinear parameters (premise parameters) ) and the least square is used for the linear parameters in the consequent parts.

\section{Simulation Model of the Multi-Agent System}

The Fig.6. Indicates the simulation of ECC with ANFIS, if it is created in computer 3 . The output of ANFIS is used to control the solar panel. Before simulation, the excel files are converted into database agent in MATLAB command window and loaded to the workspace. Based on the magnitude of voltage received in the inputs, the decision is taken by the ANFIS. The output of ANFIS is constant value $(1,2,3,4$, and 5) and this is used to drive the multi port switch. Based on the output of ANFIS, the number of panels are added or removed in the model. The wind power generation, solar power generation and grid are connected through the circuit breakers (CB-1) and (CB-2) as shown in Fig.3.These breakers are activated based on the step pulse. In this work, these circuit breakers are controlled by ECC command. The ECC is enabled to monitor the solar voltage and wind voltage magnitude for regular intervals of time to make the decision on number of solar panels connected to the load/grid or battery based on ANFIS output.. During simulation of model shown in Fig. 6, the voltage induced in solar panel and wind generators are stored in .mat file and it is converted into excel format using MATLAB commands.

\section{A. Solar Power Generation}

In a typical solar PV module, 36 cells are connected together in series. In each module, the voltages induced in the 36 cells are added together. Series combination of 36 cells will provide $21.6 \mathrm{~V}$. To generate $230 \mathrm{~V}$ ac supply with $50 \mathrm{~Hz}$, approximately 11 modules are connected. To convert DC to $\mathrm{AC}$, inverter is used and to increase the voltage, transformer is used. Solar power generation consists of solar panel, inverter, trans-former connected to the load and circuit breaker.

\section{B. Wind Power Generation}

Self excited wind power generation scheme is used in this work. Induction generator connected in parallel with capacitor bank provides excitation to the generator. When it is connected with grid, it injects power depending upon the speed of the generator. The speed of the generator depends upon the wind speed. Wind power generation consists of a wind mill, induction generator connected to the grid through circuit breaker and load 


\section{International Journal of Science and Research (IJSR) \\ ISSN (Online): 2319-7064}

Index Copernicus Value (2013): 6.14 | Impact Factor (2015): 6.391

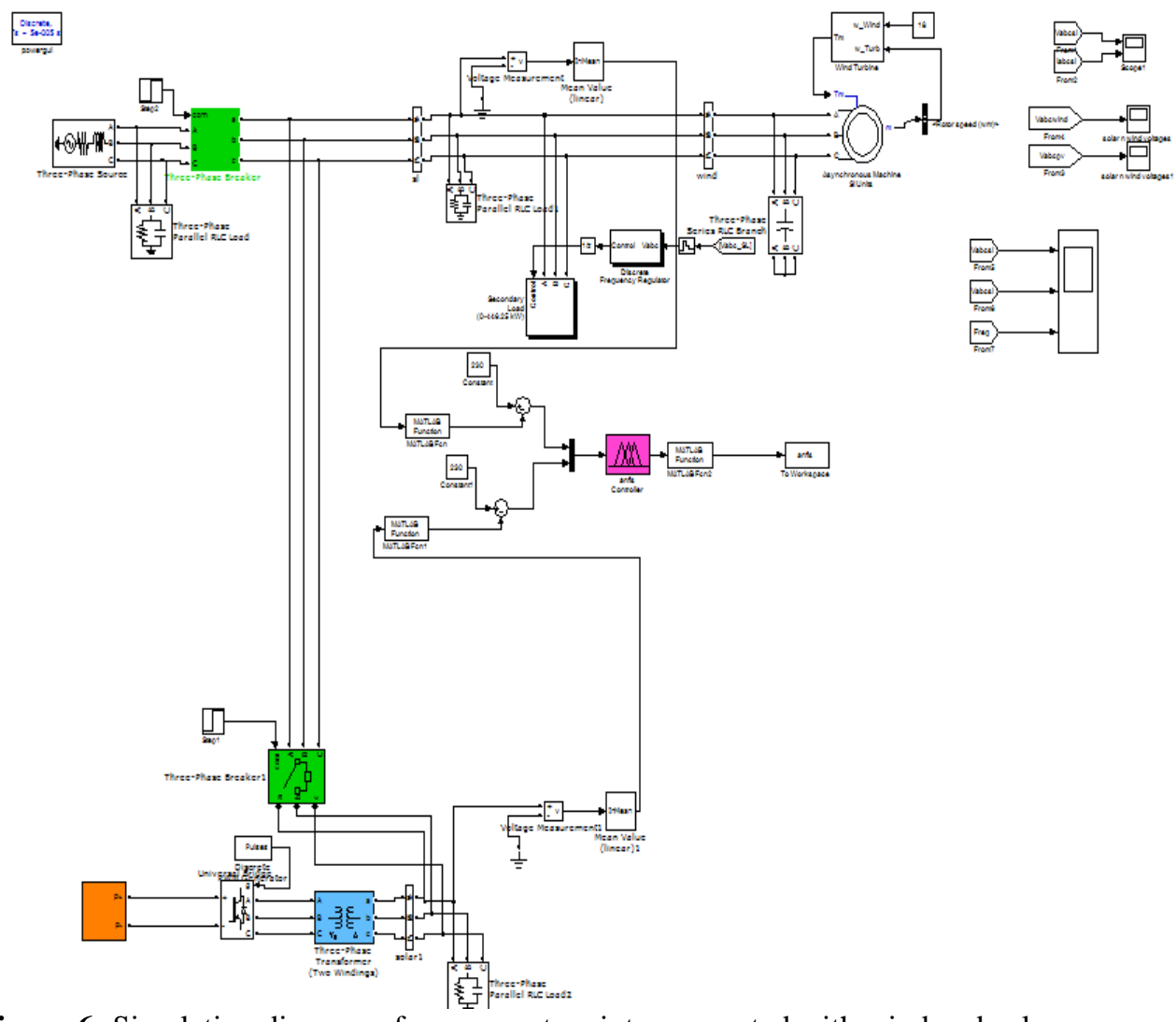

Figure 6: Simulation diagram of power system interconnected with wind and solar power generation scheme

\section{Result Analysis}

The simulation result of solar and wind power generation mentioned in Fig6. In this model, the irradiation is assumed as $1000 \mathrm{~W} / \mathrm{m}$ and the voltage generated is $230 \mathrm{~V}$ (rms) or $325.2691 \mathrm{~V}(\max )$. The wind velocity is assumed constant $(12 \mathrm{~m} / \mathrm{s})$. After the simulation, the results are stored in workspace which is converted into excel sheet using MATLAB command window in the file names "solar" and "wind". The induction generator is under self excited mode. It requires few cycles to induce the voltage because; the induction generator is not connected with the grid/source. To express this, circuit breaker (CB-1) is closed after $0.1 \mathrm{~s}$. solar power generator is connected to the grid through the circuit breaker (CB-2) after $0.3 \mathrm{~s}$. The view of database agent in excels sheets named as "solar" and "wind". This sheet is generated by the simulation model. This sheet is used as input to fuzzy logic controller during simulation. For the same simulation model, the three phase voltage and three phase current is shown in Figs. 7. The Frequency waveform is shown in fig 10.

\section{Controlled Voltage and Current:}

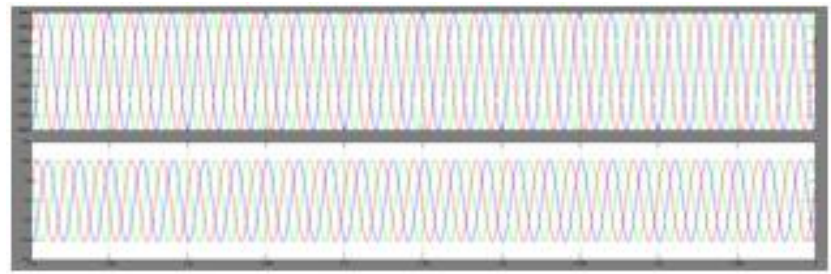

Figure 7: Voltage and current waveform of wind and solar power

\section{Wind voltage:}

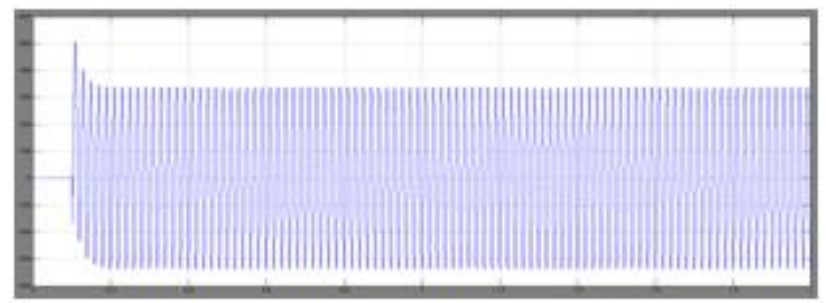

Figure 8: Voltage waveform of wind

\section{Solar Voltage:}

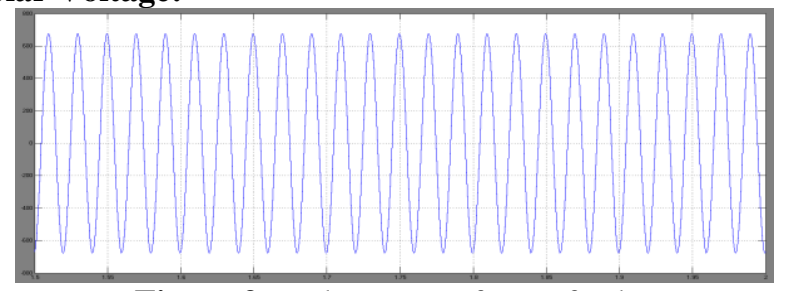

Figure 9: Voltage waveform of solar

\section{Controlled Solar and Wind Voltage and frequency:}

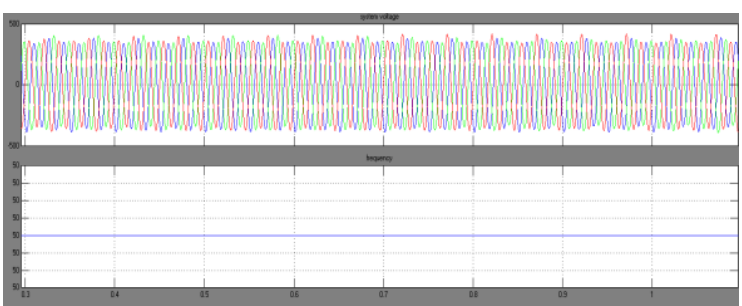

Figure 10: System Voltage and frequency

\section{Volume 5 Issue 6, June 2016 www.ijsr.net}




\section{International Journal of Science and Research (IJSR) \\ ISSN (Online): 2319-7064}

Index Copernicus Value (2013): 6.14 | Impact Factor (2015): 6.391

Total Harmonic Distortion (THD):

In this project by using Artificial Neuro Fuzzy Interface System (ANFIS) the Total Harmonic Distortion (THD) will be reduced compare to the Fuzzy Logic Controller to about $36.13 \%$.

\section{Comparison between FLC and ANFIS}

Table 2: THD comparison

\begin{tabular}{|c|c|c|}
\hline S.NO & CONTROLLER & THD (\%) \\
\hline 1 & ANFIS & 19.98 \\
\hline 2 & FLC & 31.28 \\
\hline
\end{tabular}

\section{Conclusion}

The simulation model of ECC, with ANFIS controlling the solar and wind power generation interconnected with grid using multi-agent system is described in this project. The voltage of wind and solar power are stored in a excel sheet as a database agent. ANFIS controls the switch provided in the solar panel to add/remove depending upon the voltage requirements. The results prove that the frequency fluctuations are reduced .By using FLC the THD value is $31.28 \%$ whereas by using ANFIS the THD value is $19.98 \%$. The total reduced THD value by using ANFIS compare to FLC is $36.13 \%$. These results indicate that the controlling of DER agent can be achieved both from server and client. The wind power generator and the solar power connected with local load and battery and the ECC controlled by Artificial Neuro Fuzzy Interface System (ANFSI) is used in PV system for reducing the transmission and distribution losses, complexity and THD and increases efficiency.

\section{References}

[1] H. Rongxian, L. Zhiwen, C. Yaoming, W. Fu, and R. Guoguang, "DC micro-grid simulation test platform," in Proc. 9thTaiwan Power Electron. Conf., 2010, pp. 1361-1366.

[2] S. Morozumi, "Micro-grid demonstration projects in Japan," in Proc. IEEE Power Convers. Conf., Apr. 2007, pp. 635-642.

[3] Y. Uno, G. Fujita, R. Yokoyama, M. Matubara, T. Toyoshima, and T. Tsukui, "Evaluation of micro-grid supply and demand stability for different interconnections," in Proc. Power Energy Conf., 2006, pp. $611-616$.

[4] Experience in Developing and Promoting $400 \mathrm{~V} D C$ Datacenter Power, T. V. Aldridge, Director, Energy Systems Research Lab, Intel Corporate Technology Group, Green Building Power Forum, Jun. 2009.

[5] MaximizingOverall Energy Efficiency in Data Centres, S. Lidstrom, CTO, Netpower Labs AB, Green Building Power Forum, Jun. 2009.

[6] Renewable Energy \& Data Centers, J. Pouchet, Director Energy Initiatives, Emerson Network Power., Green Building Power Forum, Jun. 2009.

[7] Development of Higher Voltage Direct Current Power Feeding System in Data Centers, K. Asakura, NTT Energy/Environment, Green Building Power Forum, Dec. 2010.
[8] Specifications for 400 V DC Power Supplies and Facility Equipment, D. Symanski, Sr. Program Manager, Electric Power Research Institute, Keiichi Hirose, NTT Facilities, and Brian Fortenberry, Program Manager, Electric Power Research Institute, Green Building Power Forum, Jan. 2010.

[9] Development of a DC Power Inlet Connector for $400 \mathrm{~V}$ DC IT Equipment, B. Davies, Director of Engineering, Anderson Power Products, Inc. Green Building Power Forum, Jan. 2011

[10] O. Castillo and P. melin, Studies in Fuzziness and Soft Computing Type2 Fuzzy Logic : Theory and Applications. New York, NY, USA: Springer-Verlag, 2008.

\section{Author Profile}

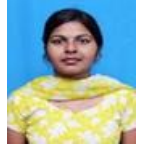

V. Sravani, received B.tech degree from Audisankara College of Engineering for Women, Gudur, Nellore (Dist), India. Currently pursuing M.Tech in Sri Venkateswara College of Engineering and Technology, Chitoor, India. The research interests include Electrical power and Energy Society.

K. Dharanisree, received M.tech from GIT, Gittam University, Visakhapatnam and Currently she is working in Sri Venkateswara College of Engineering and Technology, chitoor, India as a Assistant Professor in EEE Department. 